\title{
Caracterização físico-química, reológica, morfológica e térmica dos amidos de milho normal, ceroso e com alto teor de amilose
}

\author{
Physicochemical, rheological, morphological, and thermal characterization \\ of normal, waxy, and high amylose corn starches
}

Fernanda Hart WEBER ${ }^{2 \star}$, Fernanda Paula COLLARES-QUEIROZ ${ }^{1}$, Yoon Kil CHANG ${ }^{1}$

\begin{abstract}
Resumo
O objetivo do presente estudo foi avaliar os amidos de milho normal, ceroso e com alto teor de amilose, fabricados pela National Starch, por meio da determinação das suas características físico-químicas, morfológicas, térmicas e reológicas. $\mathrm{O}$ amido de milho com alto teor de amilose (AM) apresentou teor de amilose igual a 71\%, sendo que os valores obtidos para o amido de milho normal (M) e o amido de milho ceroso (AP) foram de 27,8 e 1,8\%, respectivamente. Traços de proteína e lipídios foram encontrados nas amostras. O amido de milho ceroso apresentou maior viscosidade máxima e uma menor tendência à retrogradação, se comparado ao amido de milho normal. $\mathrm{O}$ amido AP apresentou menor entalpia de gelatinização, como pode ser observado nas análises de calorimetria exploratória diferencial (DSC), na qual a temperatura de gelatinização foi de $75^{\circ} \mathrm{C}$ e o $\Delta \mathrm{H}$ de $3,34 \mathrm{~J} \cdot \mathrm{g}^{-1}$, e também na análise de RVA (Rapid Visco Analyser), em que a temperatura de pasta foi de $71^{\circ} \mathrm{C}$. Apresentando, dessa forma, valores inferiores aos verificados para os outros amidos. $\mathrm{O}$ valor do $\Delta \mathrm{H}$ de retrogradação do amido $\mathrm{AP}$, mostrou-se $25,8 \%$ inferior ao $\Delta \mathrm{H}$ do amido $\mathrm{M}$. O amido $\mathrm{AM}$ apresentou o valor de $26,38 \mathrm{~J} . \mathrm{g}^{-1}$, demonstrando o maior envolvimento da molécula de amilose no processo de retrogradação. Isso também foi evidenciado pela medida da força dos géis: o gel de AM apresentou força 99,18\% superior, retrogradando mais que os outros amidos. As análises de difração de raio X mostraram que os amidos de milho normal e ceroso apresentaram um padrão de difração do tipo A e o amido de milho com alto teor de amilose apresentou padrão do tipo B.
\end{abstract}

Palavras-chave: amido; milho; amilose; propriedades de pasta; DSC; microscopia.

\begin{abstract}
The objective of this work was to evaluate normal, waxy, and high amylose corn starches from National Starch, through the determination of the physicochemical, morphological, thermal, and rheological properties. The high amylose corn starch (AM) presented amylose content of $71 \%$, and the value of this component for the normal (M) and waxy (AP) corn starch was 27.8 and $1.8 \%$, respectively. Traces of protein and lipids were observed in all samples. The waxy corn starch presented higher peak viscosity and lower tendency to retrogradation when compared with the normal corn starch. The (AP) starch presented the lowest gelatinization enthalpy. This can be observed in the DSC analysis, in which the gelatinization temperature obtained was $71^{\circ} \mathrm{C}$ and the enthalpy was $3.34 \mathrm{J.g}^{-1}$. In the RVA analysis, the paste temperature was also equal to $71^{\circ} \mathrm{C}$. The retrogradation enthalpy of AP starch was $25.8 \%$ lower than the M starch. The AM starch presented a retrogradation enthalpy value equal to $26.38 \mathrm{J.g}{ }^{-1}$ validating the higher interaction of amylose molecule on the retrogradation process. This was also observed in the force of gels, in which the AM gel presented force $99.18 \%$ higher than other starches. The normal and waxy corn starches presented A $\mathrm{X}$-ray diffraction pattern and the high amylose starch presented B X-ray diffraction pattern determined by X-ray diffraction analysis.
\end{abstract}

Keywords: corn; starch; amylase; paste properties; DSC; microscopy.

\section{Introdução}

O amido é um polissacarídeo que, dentro das inúmeras aplicações, apresenta propriedades favoráveis decorrentes da segurança fisiológica, biodegradabilidade e que, pela própria abundância, já possui um papel comercial importante. Ele é a principal substância de reserva em plantas, sendo responsável por $70-80 \%$ da energia calórica consumida mundialmente. É obtido de sementes de milho, trigo, arroz, de tubérculos e raízes, particularmente de batata, batata-doce e mandioca. Os amidos naturais e os modificados têm várias aplicações em produtos alimentares como agentes adesivos, ligantes e formadores de filmes, além de atuarem como gelificantes, espessantes, retentores de umidade e retardadores da retrogradação de alguns alimentos (ZOBEL; STEFHEN, 1995; FREITAS et al., 2003).

O teor de amilose nos grânulos de amido varia de acordo com a fonte vegetal de origem, mas, geralmente, encontra-se nos intervalos de $20-30 \%$ em amidos normais de cereais. $\mathrm{O}$ amido de milho contém entre $25-28 \%$ de amilose, enquanto o de mandioca possui apenas $17 \%$. Algumas variedades de milho, cevada e arroz, referidas pelo termo ceroso ("waxy”) são constituídas totalmente

Recebido para publicação em 3/12/2007

Aceito para publicação em 14/11/2008 (003061)

${ }^{1}$ Departamento de Tecnologia de Alimentos, Universidade Estadual de Campinas - UNICAMP, Campinas - SP, Brasil

${ }^{2}$ Agroindústria, Universidade Estadual do Rio Grande do Sul - UERGS, CEP 98600-000, Três Passos - RS, Brasil, E-mail: fernanda-hart@uergs.edu.br

${ }^{*}$ A quem a correspondência deve ser enviada 
por amilopectina, enquanto outros amidos possuem teores de amilose acima de 50\% e são denominados de high-amilose (LINEBACK, 1984). Estes amidos, por apresentarem diferentes teores de amilose, possuem propriedades funcionais distintas. $\mathrm{O}$ amido de milho normal se caracteriza pela formação de um gel consistente, é bastante utilizado em sopas desidratadas e molhos que requerem viscosidade a quente. Já, para produtos que necessitam de armazenamento sob refrigeração, esse amido não é muito indicado devido à sinérese (exsudação de água), consequência do fenômeno de retrogradação. Nesses casos, é mais indicado o uso do amido de milho ceroso que apresenta maior estabilidade a baixas temperaturas, pelo fato de praticamente não possuir amilose. Os géis feitos com esse amido são fracos, altamente viscosos no cozimento, claros e coesivos (PARKER; RING, 2001; BAHNASSEY; BREENE, 1994). Os amidos high-amilose gelificam e formam filmes com facilidade devido ao alto conteúdo de amilose (COLLONA; LELOUP; BULÉON et al., 1992). Por isso, esses amidos são usados principalmente em produtos como nuggets, aos quais confere crocância e previne a penetração excessiva de óleo durante a fritura. Também são muito utilizados na indústria de balas de gomas, contribuindo com $25-50 \%$ do total de amido utilizado nas formulações.

O objetivo do presente estudo foi avaliar os amidos de milho normal, ceroso e com alto teor de amilose por meio da determinação das suas características físico-químicas, morfológicas, térmicas e reológicas.

\section{Material e métodos}

\subsection{Material}

Utilizaram-se os seguintes materiais que foram fornecidos pela National Starch (Brasil): amido de milho normal - Melojel (M); amido de milho ceroso - Amioca (AP); amido de milho com alto teor de amilose - Hylon VII (AM).

\subsection{Métodos}

\section{Determinações físico-químicas e teor de amilose}

Os lipídios totais, umidade e proteína bruta $(\mathrm{N} \times 6,25)$ foram determinados de acordo com os métodos oficiais 30.20, 44-15A e 46-12 da AACC (1995), respectivamente. O teor de amilose total foi determinado de acordo com o método de Morrison e Laignelet (1983). Os resultados foram expressos em g. $100 \mathrm{~g}^{-1}$ e realizados em triplicata.

\section{Morfologia dos grânulos}

Os amidos, após desidratação a vácuo, foram colocados em suportes de alumínio (stubs) e recobertos com uma película de ouro no aparelho Mini Sputterr Coater SC 7620, marca Polaron e observados no Microscópio Eletrônico de Varredura -MEV (LEO 440i-Leica).

\section{Determinação das propriedades de pasta}

As propriedades de pasta dos amidos M e AP foram determinadas no Rapid Visco Analyser-RVA (Newport Scientific Instruments). Os amidos em pó foram suspensos em água, na concentração de $10 \%$ de sólidos. Essa suspensão foi submetida à análise pelo Método Padrão 1: total de 13 minutos de teste, 1 minuto equilibrando a temperatura em $50^{\circ} \mathrm{C}$, aquecendo até $95^{\circ} \mathrm{C}$ em 7,45 minutos e resfriando até $50^{\circ} \mathrm{C}$ em 4,15 minutos, de acordo com o Manual da Newport Scientific Instruments. Os parâmetros medidos foram: viscosidade máxima, viscosidade mínima a $50{ }^{\circ} \mathrm{C}$, viscosidade final e retrogradação expressos em pascais (Pa.S) e temperatura de pasta expressa em graus centígrados. Os resultados expressam a média e o desvio padrão de 12 análises de cada amido. Não foi possível determinar as propriedades de pasta do amido de milho com alto teor de amilose (AM) devido à alta temperatura requerida para a sua gelatinização $\left( \pm 150^{\circ} \mathrm{C}\right)$ que é atingida somente sob alta pressão.

\section{Calorimetria exploratória diferencial (Diferential Scanning Calorimetry - DSC)}

Foram preparadas suspensões com concentração total de amido de 33\% (M e AP) e 66\% (AM). Os amidos M e AP foram submetidos a um ciclo de aquecimento e resfriamento de $35-120{ }^{\circ} \mathrm{C}$ a $10{ }^{\circ} \mathrm{C} /$ minuto e o amido $\mathrm{AM}$ a um ciclo de $35-180{ }^{\circ} \mathrm{C}$ a $10{ }^{\circ} \mathrm{C} /$ minuto, em que foi determinada a entalpia de gelatinização. Para a entalpia de retrogradação, as mesmas amostras foram armazenadas a $10^{\circ} \mathrm{C}$ durante 21 dias e submetidas à segunda análise em DSC, nas mesmas condições da primeira. Foram utilizadas cápsulas de alumínio fechadas e como referência uma cápsula fechada vazia e a calibração feita com Índio. O experimento foi conduzido em atmosfera dinâmica com o gás argônio a $80 \mathrm{~mL} /$ minuto. O equipamento utilizado foi o DSC-2910 TA Instruments. Além das entalpias foram obtidos os seguintes parâmetros: temperatura inicial $\left(\mathrm{T}_{0}\right)$ e temperatura de pico da gelatinização (Tp).

\section{Força do gel}

As amostras de amidos M, AP e AM foram suspensas em água na concentração de $10 \%$ de sólidos totais. As suspensões dos amidos M e AP foram gelatinizadas através do aquecimento em banho-maria (Dubnoff TE 053, Tecnal, Brasil) em ebulição durante 15 minutos sob agitação mecânica (Fisatom, 720, Brasil), a $800 \mathrm{rpm}$. A suspensão do amido AM foi gelatinizada em reator Pressure Reaction Apparatus $\mathrm{n}^{\circ} 4501$, sob pressão de 55 psi, à temperatura de $150{ }^{\circ} \mathrm{C}$. Com o auxílio de uma seringa de $60 \mathrm{~mL}$ foram transferidos $25 \mathrm{~mL}$ do gel para frascos cilíndricos de alumínio (altura $6,5 \mathrm{~cm}$ e diâmetro $3,5 \mathrm{~cm}$ ). Foram realizadas 10 repetições para cada gel da medida de força (g.f), que foi feita no Texturômetro Stable Micro-System TA-XT2. Foi utilizado um probe cilíndrico $(\mathrm{P} / 0,5)$ na temperatura de $25^{\circ} \mathrm{C}$ e nas seguintes condições experimentais propostas pelo software do equipamento:

I) Velocidade do teste: $0,5 \mathrm{~mm} / \mathrm{s}$;

II) Velocidade de pré-teste (velocidade a que o probe desce até chegar à amostra): $1,0 \mathrm{~mm} / \mathrm{s}$; 
III) Velocidade de pós-teste (velocidade em que o probe volta à posição inicial ao sair da amostra): 10,0 mm/s;

IV) Força de contato (é a força inicial que o probe vai exercer na amostra para começar a registrar o gráfico): 10 g.f;

V) Distância: $8 \mathrm{~mm}$, que corresponde à profundidade de penetração do probe; e

VI) Sensibilidade do aparelho: 5 g.f (M e AP) e 10 g.f (AM).

\section{Difração de raio $X$}

O padrão de difração de raio $X$ foi obtido utilizando-se um difratômetro de raio X (Rigaku). A amostra foi colocada em um porta-amostras situado num plano a um ângulo $\theta$ de $5^{\circ}$ da fonte de raio $\mathrm{X}$ (conhecido como ângulo de Bragg). A faixa de medição foi de $5^{\circ}$ a $40^{\circ}$, com uma velocidade de $0,45^{\circ}$ /minuto, operando a $35 \mathrm{kV}$ e $15 \mathrm{~mA}$ com radiação incidente $\lambda=1.5406 \AA$ de $\mathrm{CuK} \alpha$. Os difractogramas foram obtidos num ângulo de $5^{\circ}$ a $40^{\circ}$ na escala de $2 \theta$. As porcentagens de cristalinidade, dado um padrão de referência, foram estimadas pelo software (Diffract/at by socabim V1.2) acoplado ao equipamento, segundo a Equação 1:

$\%$ de cristalinidade $=$ área dos picos área total - área do ruído

\section{Resultados e discussão}

\subsection{Composição centesimal e teor de amilose}

Os resultados obtidos para os teores de umidade, proteínas, lipídios e amilose dos amidos de milho normal e ceroso são apresentados na Tabela $1 . \mathrm{O}$ amido de milho normal apresentou $27,8 \%$ de amilose e o amido de milho ceroso $1,8 \%$, resultados semelhantes aos encontrados por Tester e Sommerville (2003). Estes amidos apresentaram apenas traços de proteína e de lipídios, sendo que o amido AP apresentou teor de lipídios $53,84 \%$ superior ao amido M. O menor conteúdo de proteína foi verificado para o amido AP.

\subsection{Morfologia dos grânulos}

As características morfológicas dos amidos utilizados neste trabalho podem ser avaliadas nas Figuras 1 a 3, a seguir.

A amostra de amido de milho padrão apresentou alta proporção de grânulos angulares (Figura 1), assim como alguns grânulos arredondados. Este amido possui grânulos com diâmetros na faixa de aproximadamente 5 a $25 \mu \mathrm{m}$, conforme reportado por Penfield e Campbell (1990).

Os grânulos de amido com alto teor de amilopectina apresentam morfologia semelhante ao amido de milho padrão, no entanto, com superfície mais rugosa (Figura 2).

Na Figura 3, pode-se observar que o amido de milho com alto teor de amilose possui grânulos mais arredondados

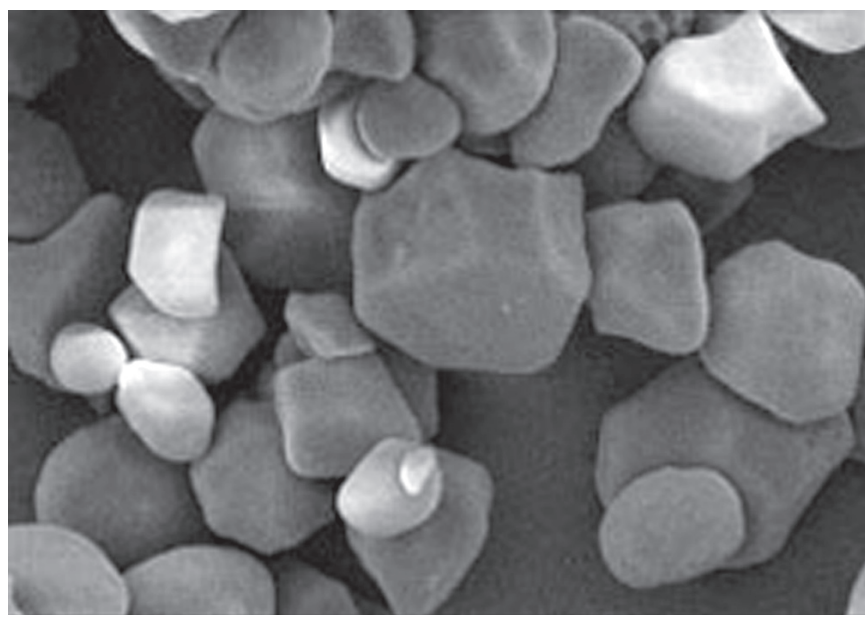

Figura 1. Micrografias dos grânulos de amido padrão, aumento de $5000 \times$.

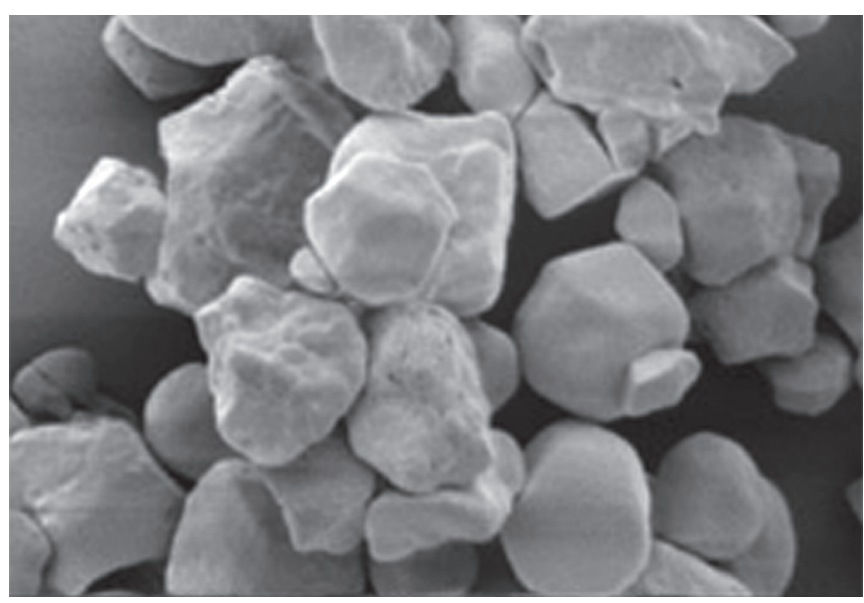

Figura 2. Micrografias dos grânulos de amido com alto teor de amilopectina, aumento de 5000×.

Tabela 1. Composição química e teor de amilose dos amidos de milho normal, ceroso e com alto teor de amilose.

\begin{tabular}{cccc}
\hline Componentes (\%) & Amido de milho normal (M) & Amido de milho ceroso (AP) & Amido de milho com alto teor de amilose (AM) \\
\hline Umidade & $13,7 \pm 0,5$ & $13,7 \pm 0,2$ & $16,03 \pm 0,04$ \\
Proteína & $0,05 \pm 0,01$ & $0,01 \pm 0,00$ & $0,06 \pm 0,00$ \\
Lipídios & $0,12 \pm 0,07$ & $0,3 \pm 0,1$ & $0,27 \pm 0,11$ \\
Amilose & $27,8 \pm 0,3$ & $1,8 \pm 0,1$ & $71,0 \pm 1,6$ \\
\hline
\end{tabular}

Média \pm desvio padrão. 
e com superfície mais lisa em relação aos amidos de milho anteriores.

\subsection{Determinação das propriedades de pasta}

A Tabela 2 mostra os valores das propriedades de pasta dos amidos de milho normal e ceroso. Verifica-se que o amido AP apresentou uma temperatura de pasta de $71^{\circ} \mathrm{C}$ e uma viscosidade máxima de 3,950 Pa.S. Os valores de temperatura de pasta e viscosidade máxima para o amido AP foram, respectivamente, $5,33 \%$ inferior e $25,65 \%$ superior aos do amido $\mathrm{M}$.

A retrogradação do amido de milho normal foi $68,06 \%$ maior que a retrogradação do amido de milho ceroso; isso ocorreu, provavelmente, devido ao maior conteúdo de amilose no grânulo de amido normal, pois se sabe que, no primeiro estágio da retrogradação, a principal molécula envolvida é a amilose, a amilopectina retrograda de forma lenta depois de alguns dias de armazenamento (BILIADERIS, 1992). A viscosidade final também foi diferente, sendo de 3,153 Pa.S para o amido $\mathrm{M}$ e de 2,056 Pa.S para o amido AP. O amido de milho ceroso apresentou uma viscosidade de $2,282 \mathrm{~Pa}$.S na quebra, ou seja, uma resistência à agitação mecânica 56\% inferior ao gel de amido de milho normal.

No amido AM, 71\% de amilose, a gelatinização ocorre somente a $128{ }^{\circ} \mathrm{C}$, impossibilitando a análise deste amido no RVA.

Bahnassey e Breene (1994) avaliaram as propriedades de pasta dos amidos de milho normal e ceroso no RVA e concluíram

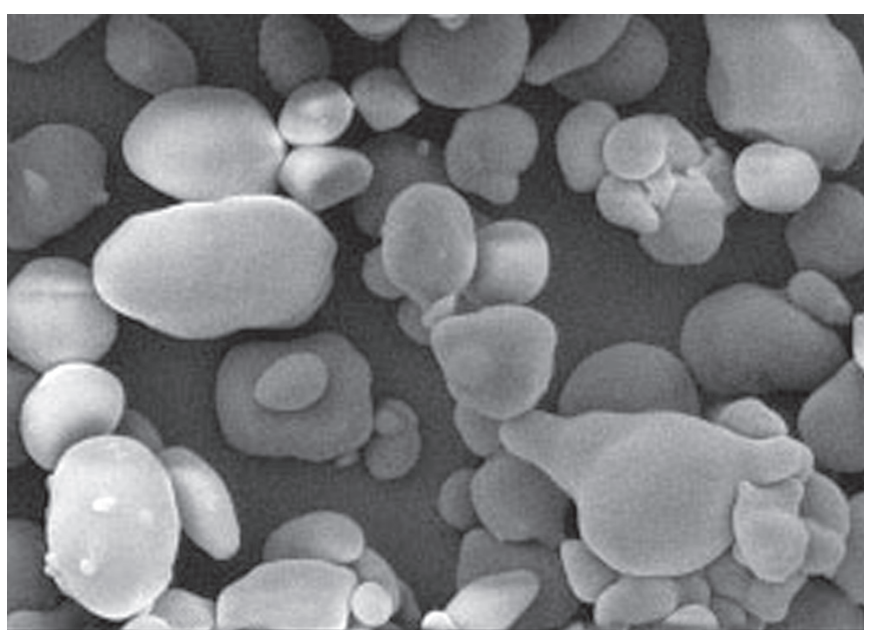

Figura 3. Micrografias dos grânulos de amido com alto teor de amilose. que o amido de milho ceroso possui uma viscosidade máxima superior, provavelmente devido à ausência da molécula de amilose. $\mathrm{O}$ amido de amaranto que possui apenas amilopectina em sua estrutura, também foi estudado e apresentou alta viscosidade máxima, semelhante à do amido ceroso. $\mathrm{O}$ amido de milho normal demonstrou uma viscosidade máxima inferior e maior viscosidade na retrogradação, provavelmente devido ao seu alto conteúdo de amilose, que restringe o inchamento e diminui, dessa forma, a viscosidade do sistema devido ao desenvolvimento de uma estrutura em rede pela agregação das moléculas de amilose (BECKER et al., 1981).

\subsection{Calorimetria exploratória diferencial (Diferencial Scanning Calorimetry - DSC)}

Os resultados de calorimetria exploratória diferencial dos amidos avaliados são apresentados na Tabela 3. Pode-se verificar que a gelatinização do amido normal (M) ocorreu na temperatura de $77,26^{\circ} \mathrm{C}$ (Tp1), já o amido AP gelatinizou em uma temperatura um pouco inferior a $75,13^{\circ} \mathrm{C}$, demonstrando o mesmo comportamento observado na análise das propriedades de pasta (item Determinação das propriedades de pasta). Como o amido AM é composto por $71 \%$ de amilose, que tem pouca mobilidade molecular, há a necessidade de temperaturas elevadas, no processo de gelatinização $\left(128,05{ }^{\circ} \mathrm{C}\right)$ para que suas ligações sejam rompidas e se estabeleçam novas ligações com a água.

Os resultados obtidos nas determinações da entalpia de gelatinização demonstram que o amido AP necessita de menor energia para que ocorra a o intumescimento das partículas pela absorção de água e elevação da temperatura (gelatinização). Estes resultados são validados pelo confrontamento com as análises de RVA, que também mostraram a menor temperatura de pasta do amido AP.

$\mathrm{O}$ valor do $\Delta \mathrm{H}$ de retrogradação do amido AP mostrou-se $25,8 \%$ inferior ao $\Delta \mathrm{H}$ do amido $\mathrm{M}$. O amido AM apresentou um $\Delta \mathrm{H}$ de retrogradação $86,75 \%$ superior ao $\Delta \mathrm{H}$ dos amidos $\mathrm{Me} \mathrm{AP}$, demonstrando o maior envolvimento da molécula de amilose no processo de retrogradação. Isso também foi evidenciado pela medida da força dos géis na análise de textura, em que o gel de AM apresenta a maior força (g.f), portanto retrogradou mais que os outros amidos (Figura 4).

Em 1992, Cooke e Gidley sugeriram que o $\Delta \mathrm{H}$ de gelatinização reflete primeiramente a perda da conformação das duplas hélices e depois a perda de cristalinidade dos amidos quando são submetidos à gelatinização. $\mathrm{O}$ amido com alto teor de amilose tem suas duplas hélices formadas basicamente pela amilose e estas requerem alta temperatura e energia para perder a sua conformação durante a gelatinização, explicando o porquê

Tabela 2. Propriedades de pasta dos amidos de milho normal (M) e ceroso (AP).

\begin{tabular}{cccccccc}
\hline Amidos & TP $\left({ }^{\circ} \mathrm{C}\right)$ & VM95 ${ }^{\circ} \mathrm{C}($ Pa.s $)$ & VF50 ${ }^{\circ} \mathrm{C}($ Pa.s $)$ & Vm $95{ }^{\circ} \mathrm{C}($ Pa.s $)$ & Quebra (Pa.s) & Retrogradação (Pa.s) & tp (minutos) \\
\hline $\mathrm{M}$ & $75 \pm 0,25$ & $2937 \pm 48,5$ & $3153 \pm 79,7$ & $1934 \pm 59,8$ & $1002 \pm 42,5$ & $1218 \pm 60,3$ \\
$\mathrm{AP}$ & $71 \pm 0,42$ & $3950 \pm 107,1$ & $2056 \pm 98,93$ & $1667 \pm 100,6$ & $2282 \pm 115,9$ & $389 \pm 85,94$ & 3,03 \\
\hline
\end{tabular}

Em que: TP = temperatura de pasta; VM $95^{\circ} \mathrm{C}=$ viscosidade máxima a $95^{\circ} \mathrm{C}$; VF $50^{\circ} \mathrm{C}=$ viscosidade final a $50{ }^{\circ} \mathrm{C}$; e tp $=$ tempo de pico. 
Tabela 3. Temperatura de pico e entalpia de gelatinização $\left(\mathrm{T}_{\mathrm{p} 1}\right.$ e $\left.\Delta \mathrm{H}_{1}\right)$ e retrogradação $\left(\mathrm{T}_{\mathrm{p} 2}\right.$ e $\left.\Delta \mathrm{H}_{2}\right)$ de suspensões de amido de milho normal, ceroso e com alto teor de amilose.

\begin{tabular}{ccccccc}
\hline Amostras & \multicolumn{3}{c}{ Gelatinização } & \multicolumn{3}{c}{ Retrogradação } \\
\cline { 2 - 6 } & $\mathrm{T}_{01}\left({ }^{\circ} \mathrm{C}\right)$ & $\mathrm{T}_{\mathrm{p} 1}\left({ }^{\circ} \mathrm{C}\right)$ & $\Delta \mathrm{H}_{1}\left(\mathrm{~J} \cdot \mathrm{g}^{-1} \mathrm{de}\right.$ amido $)$ & $\mathrm{T}_{02}\left({ }^{\circ} \mathrm{C}\right)$ & $\mathrm{T}_{\mathrm{p} 2}\left({ }^{\circ} \mathrm{C}\right)$ & $\Delta \mathrm{H}_{2}\left(\mathrm{~J} . \mathrm{g}^{-1} \mathrm{de}\right.$ amido $)$ \\
\hline $\mathrm{M}$ & 64,92 & 77,26 & 88,97 & 44,94 & 55,86 & 3,495 \\
$\mathrm{AP}$ & 68,95 & 75,13 & 3,34 & 46,20 & 57,83 & 2,593 \\
$\mathrm{AM}$ & 105,11 & 128,05 & 1075,0 & 105,45 & 141,06 & 26,38 \\
\hline
\end{tabular}

$\mathrm{AP}=$ amido de milho ceroso ( $98,2 \%$ de amilopectina); $\mathrm{M}=$ amido de milho normal (27,8\% de amilose); e AM = amido de milho com alto teor de amilose ( $71 \%$ de amilose).

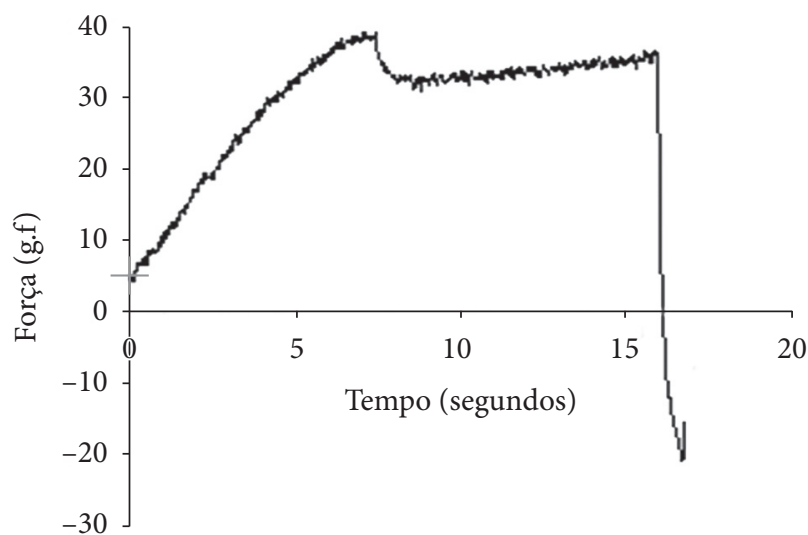

Figura 4. Força do gel de amido de milho normal, a 10\% de sólidos.

dos valores de temperatura e $\Delta \mathrm{H}$ mais altos do amido com alto teor de amilose.

\subsection{Força do gel}

Na Figura 4, encontra-se o gráfico da análise de textura do gel, no qual foi determinada a força máxima de 38,85 $\pm 2,98$ g.f para o gel de amido de milho normal. A força do gel está correlacionada com o fenômeno de retrogradação, isto é, quanto maior a força, maior a retrogradação. $\mathrm{O}$ amido de milho com alto teor de amilose apresentou uma força de gel igual a $1623 \pm 49,13$ g.f (Figura 5), demonstrando assim que a molécula de amilose está diretamente envolvida neste fenômeno. Já a força do gel de amilopectina foi de 12,64 \pm 0,36 g.f (Figura 6).

Vesterinen et al. (2002) obtiveram resultados semelhantes aos verificados no presente trabalho. Os autores realizaram medidas reológicas de géis dos amidos Hylon VII e Amioca e também observaram a maior força do gel com alto teor de amilose. Foram avaliados géis de amido Hylon VII em diferentes concentrações ( 3,5 e $8 \%)$ e verificou-se que o aumento da força ocorreu proporcionalmente à quantidade de amido adicionada. Géis de amilopectina a 10\% apresentaram força inferior aos géis de amido com alto teor de amilose a 5\%.

\subsection{Difração de raio $X$}

Através dos difractogramas de raio X (Figura 7), pode-se observar que os amidos de milho normal e ceroso apresentaram um padrão do tipo $\mathrm{A}$ e o amido de milho com alto teor de amilose apresentou padrão de cristalinidade do tipo B,

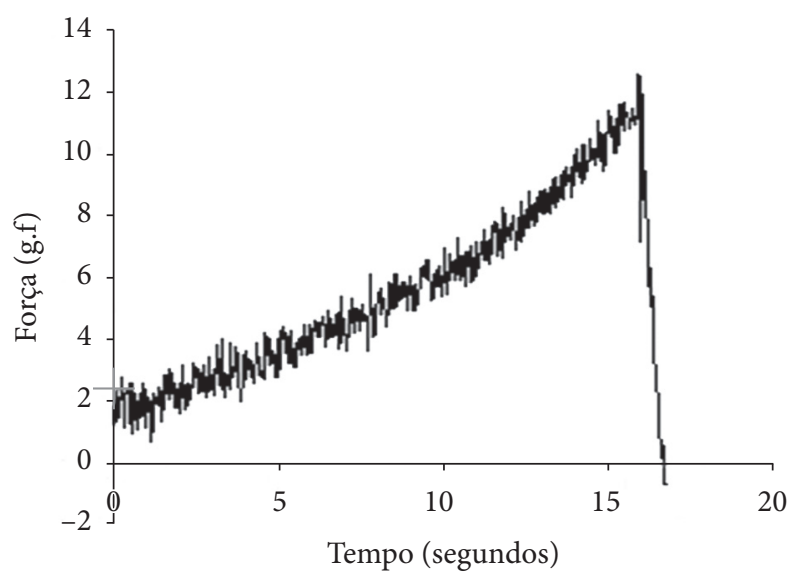

Figura 5. Força do gel de amido de milho ceroso, a 10\% de sólidos.

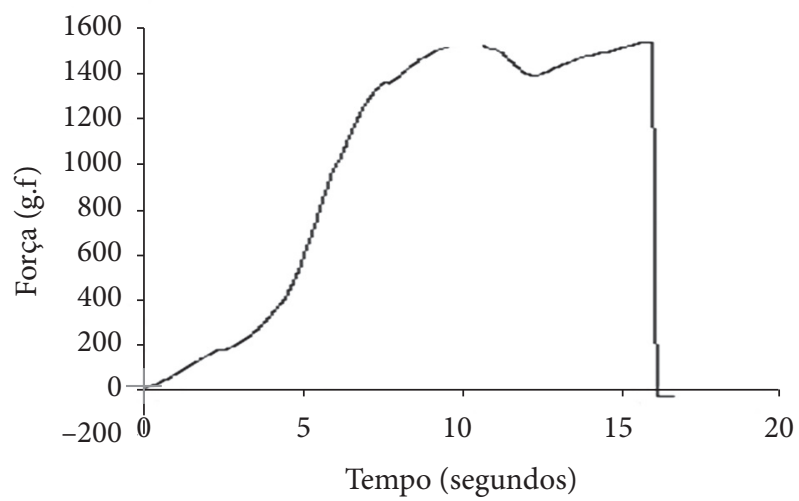

Figura 6. Força do gel de amido de milho com alto teor de amilose, a $10 \%$ de sólidos.

confirmando os resultados observados na literatura (KARIM; NORZIAH; SEOW, 2000; SHI et al., 1998).

Hizuruki (1985) estudou a correlação entre o tamanho e arranjo das cadeias de amilopectina e a estrutura cristalina dos grânulos de amido. Este pesquisador concluiu que as amilopectinas do amido tipo A têm em média uma proporção maior de moléculas com cadeias curtas do que as amilopectinas dos amidos tipo B.

Shi et al. (1998) mostraram que a amilopectina do amido ceroso e normal tem uma proporção maior de moléculas com cadeias curtas (ramificações) e estes amidos possuem um 
padrão de difração do tipo A. No entanto, o amido com alto teor de amilose apresentou uma proporção maior de cadeias longas nas suas frações ramificadas e apresentou um padrão tipo B. O fato de os amidos apresentarem padrões de difração diferentes é um indicativo de que eles possuem uma diferença na estruturação da dupla hélice que forma o cristal, e isto define suas propriedades funcionais.

$\mathrm{Na}$ Tabela 4, estão apresentados os valores de cristalinidade dos amidos avaliados. Pode-se verificar que o amido de milho com alto teor de amilose apresentou menor cristalinidade que os demais amidos. $\mathrm{O}$ amido de milho ceroso apresentou cristalinidade 52\% superior, este é o amido que possui maior quantidade de amilopectina que, segundo Zobel (1988), é a responsável pela parte cristalina do grânulo. Teixeira (2002) apresentou resultados de difração de raio $\mathrm{X}$ para os amidos de milho normal e ceroso, semelhantes aos observados no presente trabalho. Os resultados observados na difração de raio X se mostraram coerentes aos observados nas análises de RVA e DSC e estão de acordo com dados da literatura.

Segundo Shi et al. (1998) uma cristalinidade menor não é necessariamente sinônimo de menor ordenação molecular nos grânulos e sim um indicativo do menor tamanho dos cristais.

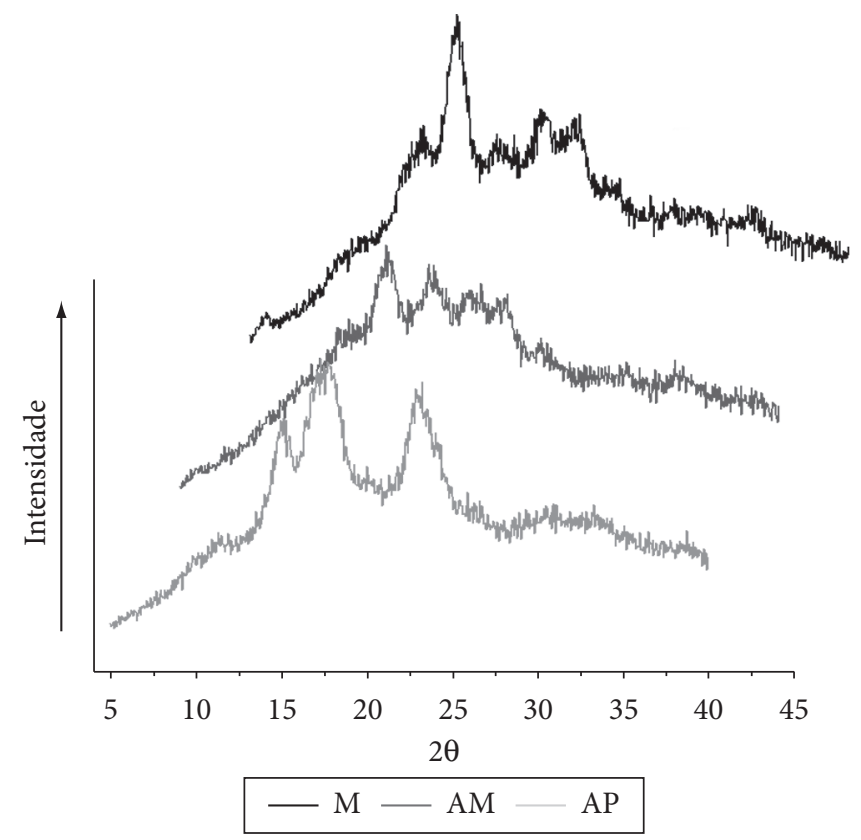

Figura 7. Difractogramas de raio X dos amidos de milho normal (M), com alto teor de amilose (AM) e ceroso (AP).

Tabela 4. Cristalinidade (\%) dos amidos de milho normal (M), ceroso (AP) e com alto teor de amilose (AM).

\begin{tabular}{cc}
\hline Amostra & Cristalinidade (\%) \\
\hline M & 13,38 \\
AP & 21,62 \\
AM & 10,25 \\
\hline
\end{tabular}

\section{Conclusões}

Os amidos avaliados apresentam morfologia característica de cada espécie.

O amido de milho ceroso apresenta viscosidade máxima superior e menor tendência à retrogradação que o amido de milho normal e necessita de menor energia para gelatinizar. $\mathrm{O}$ menor valor de $\Delta \mathrm{H}$ do amido de milho ceroso e a maior força de gel do amido de milho com alto teor de amilose evidenciam o maior envolvimento da amilose no processo de retrogradação.

\section{Referências bibliográficas}

AMERICAN ASSOCIATION OF CEREAL CHEMISTS - AACC. Approved methods of the American Association of Cereal Chemists. $9^{\text {th }}$ ed. St. Paul, 1995. v. 1 e 2.

BAHNASSEY, Y. A.; BREENE W. M. Rapid Visco-Analyzer (RVA) Pasting profiles of wheat, corn, waxy corn, tapioca and amaranth starches in the presence of konjac flour, gellan, guar, xanthan and locust bean gums. Starch/Starke, v. 4, p. 134-141, 1994.

BECKER, R. E. L. et al. A compositional study of amaranth grain. Journal Food Science, v. 46, p. 1175-1180, 1981.

BILIADERIS, C. G. Structures and fase transitions of starch in food systems. Food Technology, v. 46, n. 6, p. 98-109, 1992.

COLLONA, P.; LELOUP, V.; BULÉON, A. Limiting factors of starch hidrolysis. European Journal of Clinical Nutrition, v. 46, p. 17-32, 1992.

COOKE, D.; GIDLEY, M. J. Loss of crystalline and molecular order during starch gelatinization: origin of the enthalpic transition. Carbohydrate Research, v. 227, p. 103-112, 1992.

FREITAS et al. A rheological description of mixtures of a galactoxiloglucan with high amylose and waxy corn starches. Carbohydrate polymers, v. 51, p. $25-32,2003$.

HIZURUKI, S. Relationship between the distribution of the chain length of amylopectin and the crystalline structure of starch granules. Carbohydrate Research, v. 141, p. 295-306, 1985.

KARIM, A. A.; NORZIAH, M. H.; SEOW, C. C. Methods for the study of starchretrogradation. Food Chemistry, v. 71, p. 9-36, 2000.

LINEBACK, D. R. The starch granule: organization and properties. Bakers Digest, v. 58, n. 2, p. 16-21, 1984

MORRISON, W. R.; LAIGNELET, B. Na improved colorimetric procedure for determiningapparent and total amylose in cereal and other starches. Journal of Cereal Science, v. 1, p. 9-20, 1983.

PARKER, R.; RING, S. G. Aspects of the physical chemistry of starch. Jouranl of Cereal Science, v. 34, p. 1-17, 2001.

PENFIELD, M. P.; CAMPBELL, A. M. Experimental food science. $3^{\text {rd }}$ ed. San Diego: California Academic Press, 1990. 541 p.

SHI, Y. C. et al. Molecular structure of a low-amylopectin starch and other high-amylose maize starches. Journal of Cereal Science, v. 27, p. 289-299, 1998.

TEIXEIRA, M. A. V. Amidos quimicamente modificados empregados na substituição de gorduras em alimentos. 2002. 116 p. Tese (Doutorado em tecnologia de Alimentos) - Faculdade de Engenharia de Alimentos, Unicamp, 2002.

TESTER, R. F; SOMMERVILLE, M. D. The effects of non-polysaccharides on the extent of gelatinization, swelling and alfa-amylase hydrolysis of maize and wheat starches. Food Hydrocolloids, v. 17, p. 41-54, 2003.

VESTERINEN, E. et al. Structural properties in relation to oral enzymatic digestibility of starch gels based on pure starch components and high amylose content. Food Hydrocolloids, v. 16, p. 161-167, 2002.

ZOBEL, H. F. Molecules to granules: a comprehensive starch review. Starch/ Starke, v. 40, n. 2, p. 44-50, 1988.

ZOBEL, H. F.; STEPHEN, A. M. Starch: structure, analysis, and application. ZOBEL, H. F.; STEPHEN, A. M. Starch: structure, analysis and pplication. In: STEPHEN, A. M. Food polyssacharides and their application. New York: Marcel Dekker, 1995. p. 19-66. 